\title{
Leucoencefalopatía multifocal progresiva en pacientes con sida. Hepatotoxicidad de la terapia de alta eficacia (TARGA) en pacientes con coinfección por VHB o VHC
}

\author{
A. BLANCO BARRIOS, F. ZANCADA DÍAZ DE ENTRE-SOTOS, A. GUTIÉRREZ \\ VIVAS, N. CALDERÓN MARIÑO
}

Servicio de Medicina Interna. Hospital Virgen del Puerto. Plasencia. Cáceres

\begin{abstract}
RESUMEN
La leucoencefalopatía multifocal progresiva (LMP) es un criterio diagnóstico de sida. Afecta al 1-8\% de los pacientes con sida (según las series), con supervivencias de 4-6 meses antes de las terapias antirretrovirales de gran actividad (TARGA). Se observa sobre todo en pacientes usuarios a drogas por vía parenteral, con inmunodeficiencia avanzada (Carga vírica: $\log 5$ copias/ $\mathrm{ml} \mathrm{y} \mathrm{CD4}<150 / \mathrm{mm}^{3}$ ). Parece que sólo los pacientes bajo tratamiento con TARGA consiguen supervivencias más prolongadas. Las hepatitis víricas no son el único problema que se ha visto en pacientes con infección por VIH. Infecciones oportunistas y neoplasias, tales como el linfoma y sarcoma de Kaposi y problemas biliares han sido observados, si bien estos no son muy frecuentes, gracias a los nuevos tratamientos antirretrovirales. Sin embargo en pacientes con Hepatitis B o C el tratamiento antirretroviral puede causar mayor hepatotoxicidad.
\end{abstract}

PALABRAS CLAVE: Leucoencefalopatía multifocal progresiva en pacientes con sida. Hepatoxicidad de TARGA en hepatitis B o C.
PROGRESSIVE MULTIFOCAL LEUCOENCEPHALOPATHY IN AIDS PATIENTS. HEPATOTOXICITY OF HAART IN PATIENTS WITH HEPATITIS B OR C

\section{ABSTRACT}

Progressive multifocal leukoencephalopathy (PML) develops in 1$8 \%$ of patients with AIDS, for which it is a disease-defining condition. $P M L$ presents mainly in severely immunocompromised male intravenous drug users, having viral loads greater than $\log 5$ RNA copies $/ m L$ and CD4 populations lower than 150 cells $/ \mathrm{mm} 3$. Death of AIDS patients with PML occurred after only 4 to 6 months before the introduction of highly active antiretroviral therapies (HAART), the only ones that have shown to prolong survival. Viral hepatitis is not the only liver condition affecting patients with AIDS, opportunistic infections and neoplasms, such as lymphoma and Kaposi's sarcoma, as well as biliary disease are also encountered but, fortunately, they are currently less frequent as a result of the new antiretroviral treatments. The risks of HAART hepatotoxicity in patients with hepatitis B or C have been studied by several groups.

KEY WORDS: Progressive multifocal leucoencephalopathy. AIDS. Hepatotoxicity of HAART in patients with hepatitis B or $C$.

Blanco Barrios A, Zancada Díaz de Entre-Sotos F, Gutiérrez Vivas A, Calderón Mariño N. Leucoencefalopatía multifocal progresiva en pacientes con sida. Hepatotoxicidad de la terapia de alta eficacia (TARGA) en pacientes con coinfección por VHB o VHC. An Med Interna (Madrid) 2005; 22: 376-378.

\section{INTRODUCCIÓN}

Las enfermedades más frecuentes entre las encefalopatías predominantemente focales en pacientes VIH con infección avanzada son: la toxoplasmosis cerebral, la leucoencefalopatía multifocal progresiva (LPM) y el linfoma cerebral primario. Se puede afirmar que más del $90 \%$ de pacientes con inmunodepresión grave y una lesión cerebral focal, presentará una de estas tres enfermedades. En España, según el Registro Nacional de Sida, la toxoplasmosis cerebral representa el 7\%, la LMP el $3 \%$ y el linfoma cerebral primario $0,3 \%$. La leucoencefalopatía multifocal progresiva (LMP) es un criterio diagnóstico de sida (1). Es una enfermedad desmielinizante de curso progresivo, causada por la reactivación del papovirus JC. Es la cuarta causa de lesión del SNC en estos pacientes. La aparición de la infección por VIH ha motivado un incremento de al menos 20 veces su prevalencia, y ésta ha seguido un curso paralelo a la infección por VIH. Afecta al 1-8\% de los pacientes con sida, con supervivencias de 4-6 meses antes de las terapias antirretrovirales de gran actividad (TARGA). Se observa sobre todo en pacientes usuarios a drogas por vía parenteral, con inmunodeficiencia avanzada (CV log 5 copias/ $\mathrm{ml} \mathrm{y} \mathrm{CD} 4<150 / \mathrm{mm}^{3}$ ). Los tratamientos adyuvantes ensayados han sido inefectivos (citarabina, cidofovir, interferon, topetocan), aunque los estudios realizados hasta el momento se han realizado con pequeñas series de pacientes. Se trata de una enfermedad frecuentemente fatal a corto plazo, se han observado supervivencias prolongadas en pacientes bajo tratamiento con TARGA (17-48 meses). (2,4). La enfermedad hepática es un problema a considerar en pacientes coinfectados por el HIV y virus de la hepatitis. En algunos pacientes coinfectados por VHC se ha encontrado una mayor hepatotoxicidad con TARGA, sobre todo en aquellos regímenes que incluían ritonavir (3). Hasta hace pocos años, el diagnóstico se

Trabajo aceptado: 13 de abril de 2005 
basaba en criterios histopatológicos de biopsias cerebrales estereoatáxicas, sin embargo, Giesen et al y Weber et al han señalado que la detección del ADN del virus JC en LCR, con especificidad y sensibilidad muy altas, pueden obviar la biopsia para el diagnóstico de la LMP $(4,5)$.

\section{CASO APORTADO}

Paciente de 37 años, remitido desde su Centro de Atención Primaria por deterioro del estado cognitivo. A. patológicos: Usuario de drogas fumadas (cannabis, opio) y consumo de $>2$ paquetes de cigarrillos/día, niega consumo de drogas vía parenteral, aunque no es fiable dado su estado cognitivo y su familia no lo había visto desde hacía 15 años y no lo sabe. Raquitismo en la infancia. No alergias medicamentosas conocidas. No intervenciones quirúrgicas.

E. actual: paciente que hace 15 años desapareció del domicilio familiar. Una semana antes del ingreso, consiguen encontrarlo en un estado lamentable, la familia refiere que está como "ido", que aparentemente no ve bien, tantea buscando cuando tiene algo enfrente, precisa ayuda para comer, vestirse, etc., presenta debilidad generalizada. Además en los días previos al ingreso, no puede mover el brazo izquierdo. Contesta con monosílabos, y no parece consciente de su situación.

E. física: consciente, hemodinámicamente estable, desorientación temporo-espacial, amnesia para hechos recientes, hemiapnosia homónima izquierda, paresia de miembro superior izquierdo e incordinación motora con dismetría, marcha inestable con aumento de la base de sustentación, Romberg negativo. Caquéctico. No soplos carotídeos. AC y pulmonar normal. Abdomen blando, no doloroso, se palpan hepatomegalia a unos 3 traveses de dedo del reborde costal y esplenomegalia de unos 4 traveses de dedo. EE: no signos de venopunción, pulsos periféricos presentes, resto de exploración anodina salvo paresia de MSI y tatuajes múltiples.

Pruebas complementarias: analíticas: bioquímica: Glucemia 74 mg/dl, GOT 40, GPT 49, LDH 354, GGT 182, fosfatasa alcalina 281 U/l, bil total 0,40, CPK 55, resto de analítica norma, incluyendo ácido folico, Vit B12 y hormonas tiroideasl. Proteínas totales 7,4 g/dl, Proteinograma: albúmina $3.89 \mathrm{~g} / \mathrm{dl}$, gammaglobulinas $1,76 \mathrm{~g} / \mathrm{dl}(\mathrm{N} \mathrm{0,69-}$ 1,72), resto normal. Kappa en suero 4.10 (N 1,7-3,7), Lambda 2,46 g/dl (N 0,9-2,1), cociente k/l de 1.7 (N 1,35-2,65). Inmunoglobulinas: IgG 1670 (N 690-1530), resto normales. Hemograma: leucocitos totales 2300 (N 52.2, L 32.5, Mo 12.7\%), hematíes 4,03 x 10\% $\mathrm{mm}^{3}$, Hb 12 $\mathrm{g} / \mathrm{dl}$, Hto $35,2 \%$, plaquetas $91.000 / \mathrm{mm}^{3}$, ctes corpusculares normales. Citología en sangre periférica: agregados de plaquetas. Fórmula manual: $48 \%$ de segmentados, $44 \%$ LF, $3 \%$ Monos, $2 \%$ eos. Linfocitos grandes con gran citoplasma basófilo sugerente de viriasis. Estudio de coagulación: Act. protrombina 100\%, TPTA 35, fibrinógeno 380 $\mathrm{mg} / \mathrm{dl}$. VSG $50 \mathrm{~mm}$ en la primera hora. Serologías: Brucella, Coxiella, leishmania y lúes negativas, $\mathrm{HbcAg}$ negativo, Ac anti-VHC positivo, AC VIH 1-2 positivo, Ag p-24 0.14 (negativo), Contaje de linfocitos: CD4 6\% (totales $68 \mathrm{~mm}^{3}$ ), CD8 79\% (totales $893 / \mathrm{mm}^{3}$ ), cociente CD4/CD8 0.08. Carga viral: 130.000 copias de ARN/ ml. Screening autoinmunidad: ANA $+1 / 40$ con patrón p-ANCA, resto de estudios de autoinmunidad negativos. Crioglobulinas positivas, criofibrinógeno positivo, estudio de trombofilia: homocisteina en plasma 17,8 mic$\mathrm{mol} / \mathrm{l}(\mathrm{N}$ hasta 12,4$)$, patrón heterocigoto. Resto dentro de la normalidad. Gasometría basal: $\mathrm{pH} 7.45, \mathrm{pO}_{2} 88,4 \mathrm{~mm}$ de $\mathrm{Hg}, \mathrm{pCO}_{2} 35,2$, bicarbonato $24,6 \mathrm{mmol} / \mathrm{L}$, Sat $\mathrm{O}_{2} 968 \%$.

Punción lumbar: se obtiene líquido claro, con presión normal. VDRL negativo, glucosa 67 , proteínas totales $49,8 \mathrm{mg} / \mathrm{dl}$, no se observan células (determinación simultánea en plasma: proteínas 6,8 $\mathrm{g} / \mathrm{dl}$, albúmina 3,6 g/dl).

Pruebas de imagen: Rx de tórax: opacidad generalizada, pequeña zona sugerente de bronquiectasias en LSD.

TAC craneal: atrofia ligera, de predominio cortical, más marcada de lo esperable para la edad del paciente. Lesiones hipodensas, con forma de cuña y localización subcortical en la sustancia blanca del lóbulo frontal derecho, regiones postcentrales del lóbulo parietal del mismo lado e izquierdo. En la sustancia blanca periventricular izquierda de la corona radiada se observa lesión redondeada de pequeño tamaño. Lesión hipodensa en hemisferio cerebeloso izquierdo sin efecto masa ni signos de sangrado. Todas estas lesiones se asocian a signos de atrofia focal y ninguna presenta captación de contraste. Hallazgos compatibles con infartos subcorticales y lacunares múltiples. Dada la edad del paciente y los antecedentes pudieran estar relacionados con vasculitis.

$R M N$ craneal: retracción cortical mayor de lo esperado para su edad. Infarto lacunar en la corona radiada izquierda que tracciona hacía sí el ventrículo lateral, sugerente de cronología antigua. Lesión corticosubcortical frontal posterior derecha con extensión a la corona radiada y centro semioval, sugerente de infarto de posible cronología subaguda tardía en el territorio de una rama cortical de la arteria cerebral media derecha. Leucopatía isquémica por enfermedad de pequeño vaso en las áreas retroatriales. Dudosa lesión en el pedúnculo cerebeloso medio izquierdo, que aunque sugerente de ser isquémica, no permite excluir la posibilidad de una enfermedad desmielinizante.

ECG y ecocardiograma: normal. Ecocardiograma transesofágico: imposible realización por falta de colaboración del paciente.

Hemocultivos, cultivo de esputo, tinción de auramina en esputo: Negativos.

Evolución: durante su estancia hospitalaria el paciente permaneció hemodinámicamente estable, sin cambios en el cuadro neurológico. Durante su ingreso presentó candidosis oral, que se trató con fluconazol vía oral. Ante la sospecha de probable vasculitis se inició tratamiento con corticoides (prednisona $1 \mathrm{mg} / \mathrm{kg} /$ día), sin mejoría clínica. Al cabo de unos días presenta empeoramiento del cuadro con alteración en la articulación del lenguaje e incremento de paresia en hemicuerpo izquierdo (afectando sobre todo a MSI). En la exploración neurológica: lenguaje limitado a sonidos guturales. Obedece a órdenes sencillas (apretar la mano....) de forma inconstante. Pupilas mióticas, escasamente reactivas, sin objetivarse oftalmoplejia. ROT conservados, asimétricos (> izquierdos). Motilidad espontánea conservada en miembros derechos. Ante estímulos nociceptivos existe una retirada con MII, sin movilidad en MSI, aunque expresa facies de dolor. RCP derecho extensor, izquierdo indiferente.

Arteriografíanormal. Iniciamos tratamiento con TARGA (AZT + $3 \mathrm{TC}+$ Nelfinavir $(750 \mathrm{mg} / 8 \mathrm{~h})$ y profilaxis frente a P. Carinii con cotrimoxazol y ácid fólico, suspendiendo los corticoides.

Durante el presenta fiebre elevada sin foco aparente, por lo que solicitamos estudios de fibre de origen desconocido e iniciamos tratamiento empírico con Imipenem a dosis de $1 \mathrm{gr}$ cada 8 horas.

Ecografía Abdominal: hígado aumentado de tamaño con ecogenicidad homogénea y bordes lisos, no se observan LOES. Esplenomegalia homogénea (diámetro bipolar de $13 \mathrm{~cm}$ ). Resto normal.

Cultivo de esputo negativo, tinción de auramina en esputo y orina negativos, urocultivo negativo. Lowenstein de esputo y orina negativos. Coprocultivos y parásitos negativos

Serologías: Ig M CMV positivo, Ig G CMV > 250, Ig G Toxoplasma 31.3 (N 0-10 UI). Rosa de Bengala positivo. Coombs Brucella spp 1/ 5120, aglutinación de Brucella spp 1/ 640. Hemocultivos (x3): Se aisla S. epidermidis (staepi) sensible a Vancomicina, Teicoplanina y tetraciclinas. Una segunda serie de HC (x3) se aisla Staphylococcus simulans, sensible a casi todos los fármacos.

Analítica: bioquímica: glucemia $235 \mathrm{mg} / \mathrm{dl}$, triglicéridos 324 mg/dl, K 5,40 mEq/l, calcio 7,5 mg/dl, GOT 148, GPT 129, LDH 1292 U/l, GGT 140, CK 215 U/l resto de valores bioquímicos dentro de la normalidad. Hemograma: Leucos totales 2200 (N66,3\%, L28,9\%), Htíes 3,00 mill/micrL, $\mathrm{Hb} 8,4 \mathrm{~g} / \mathrm{dl}$, Hto $24,9 \%$, plaquetas $65.000 / \mathrm{mm}^{3}$. Proteínas totales 6,3 g/dl con hipergammaglobulinemia policlonal en el proteinograma, VSG $99 \mathrm{~mm}$ en la primera hora. Punción de LCR: Bioquímica similar a la anterior. Papovirus JC positivo por PCR.

$R M N$ craneal $\left(2^{\mathrm{a}}\right)$ : lesiones múltiples y asimétricas de sustancia blanca, supra e infratentoriales, que en función de la clínica sospechosa y dados los antecedentes habría que valorar como leucoencefalopatía multifocal progresiva en fase avanzada (LMP). Las lesiones han aumentado levemente en su expresividad respecto al estudio anterior y una lesión en el centro de la protuberancia de nueva aparición. Zonas 
de necrosis con licuefacción en una pequeña zona de centro semioval izquierdo y en región periatrial derecha. Esta última lesión es muy amplia y confluente desde región frontal hasta región occipital.

Evolución: Ante el empeoramiento clínico del paciente, persistiendo la fiebre, dificultad para la movilización y la deglución con episodios de atragantamiento, los hallazgos analíticos y pruebas de imagen, se añaden al tratamiento: doxiciclina, gentamicina y vancomicina con deterioro progresivo, causando exitus.

\section{DISCUSIÓN}

La leucoencefalopatía multifocal progresiva (LMP) es un criterio diagnóstico de sida (1). Es una enfermedad desmielinizante de curso progresivo, causada por la reactivación del papovirus JC. La aparición de la infección por VIH ha motivado un incremento de al menos 20 veces su prevalencia, y ésta ha seguido un curso paralelo a la infección por VIH. Afecta al $1-8 \%$ de los pacientes con sida, con supervivencias de 4-6 meses antes de las terapias antirretrovirales de gran actividad (TARGA). Se observa sobre todo en pacientes usuarios a drogas por vía parenteral, con inmunodeficiencia avanzada (CV $\log 5$ copias/ $\mathrm{ml}$ y CD $4<150 / \mathrm{mm}^{3}$ ). Los tratamientos adyuvantes ensayados han sido inefectivos (citarabina, cidofovir, interferon, topetocan), aunque los estudios realizados hasta el momento se han realizado con pequeñas series de pacientes. Se trata de una enfermedad frecuentemente fatal a corto plazo, se han observado supervivencias prolongadas en pacientes bajo tratamiento con TARGA (17-48 meses). (2) . Las enfermedades más frecuentes entre las encefalopatías predominantemente focales en pacientes VIH con infección avanzada son: La toxoplasmosis cerebral, la leucoencefalopatía multifocal progresiva (LPM) y el linfoma cerebral primario. Se puede afirmar que más del $90 \%$ de pacientes con inmunodepresión grave y una lesión cerebral focal, presentará una de estas tres enfermedades. En España según el Registro Nacional de Sida, la toxoplasmosis cerebral representa el 7\%, la LMP el $3 \%$ y el linfoma cerebral primario $0.3 \%$. Las tres enfermedades focales tienen típicamente un curso subagudo y pueden ser indistinguibles desde el punto de vista clínico. Los déficits neurológicos pueden ser similares en las tres enfermedades. Sin embargo la LMP, al menos al comienzo, no se acompaña de alteración en el nivel de conciencia ni síntomas generales. Las pruebas de neuroimagen nos pueden ayudar en el diagnóstico, así en la RM la LMP afecta fundamentalmente a la sustancia blanca adyacente a la corteza y no produce efecto masa ni captación de contraste. No existe ningún tratamiento curativo, aunque con la terapia antirretroviral de alta eficacia (que contengan AZT) parece mejorar la supervivencia (1). Giesen et al, en 1197, plantearon 5 criterios diagnósticos de los cuales, es necesario que se cumplan cuatro de ellos para llegar al diagnóstico de la enfermedad, sin necesidad de estudios histopatológicos: a) infección por VIH; b) sexo masculino; c) clínica neurológica multifocal (signos piramidales, extrapiramidales, cerebelosos, alteración de la función cognitiva, alteraciones en el habla, etc.); d) pruebas de neuroimagen compatible; y e) virus JC detectable por PCR en el LCR. Hoy en día, una clínica y estudios de imagen compatibles con PCR positiva para el VJC nos orientan hacia el diagnóstico sin tener que recurrir a la biopsia (4).

El problema lo encontramos en pacientes coinfectados por el virus de la hepatitis $\mathrm{B}$ o $\mathrm{C}$, con problemas hepáticos, en estos pacientes puede haber una mayor hepatotoxicidad con los regímenes antirretrovirales (3).

En nuestro caso, las pruebas de imagen no fueron concluyentes en un principio, retrasando el inicio de la terapia antirretroviral (TARGA), además se añadieron alteraciones en la función hepática (probablemente secundarias a 1 tratamiento antirretroviral) y complicaciones infecciosas que desencadenaron un fatal desenlace.

En un paciente varón con infección por VIH e importante grado de inmunosupresión, que presenta un cuadro subagudo neurológico con déficits focales, hemos de sospechar: Toxoplasmosis, linfoma cerebral primario y LPM. Los métodos de imagen y la PL nos ayudaran al diagnóstico sin tener que llegar a la biopsia.

A veces un error en la interpretación de las pruebas diagnósticas, pueden llevar a un retraso en el inicio del tratamiento Es necesario evaluar conjuntamente la clínica del paciente y los resultados de los métodos diagnósticos y no al contrario.

La clínica, métodos de imagen y el aislamiento del VJC en LCR orientan hacia el diagnóstico, sin tener que recurrir a métodos invasivos.

La coinfección por virus de la hepatitis B o C puede aumentar la hepatotoxicidad con los tratamientos antirretrovirales.

Aunque de todas formas la evolución de la LMP es mala a corto plazo, a pesar de que la terapia de alta eficacia haya conseguido aumentar la supervivencia.

Lo que no podemos explicar en nuestro paciente, es como adquirió la Brucelosis, llevando tanto tiempo ingresado en el Hospital. Aunque con el grado de inmunosupresión que presentaba, cualquier infección era posible.

\section{AGRADECIMIENTOS}

Queremos dar las gracias a Juan Monje Martín, fotógrafo del Hospital, por su colaboración en el apoyo iconográfico que nos ha prestado.

\section{Bibliografía}

1. Aliaga Martínez L. Encefalopatías predominantemente focales. Aspectos clínicos y microbiológicos de la infección por VIH. Nuevos avances en el tratamiento del sida. Alcalá la Real: Formación Alcalá, 2001; 108-111.

2. Montes Santiago J, Pérez Fernández E, González Vázquez L, Morano Amado L, Fernández Martín J, Asorey Caballeira A, et al. Leucoencefalopatía multifocal progresiva en pacientes con sida: ¿hay algún cambio en pacientes con TARGA? An Med Interna (Madrid) 2002; 19: 230-233.

3. Bonacini M. Management issues in patients coinfected whith $\mathrm{C}$ virus and
HIV. The AIDS Reader 2002; 1.

4. Robles JP, Nuño C, Camero B, Díaz Curiel M. Leucoencefalopatía multifocal progresiva: un diagnóstico no invasivo. Med Clin (Barc) 2000; 115: 199.

5. Asensi V, Cartón JA, Maradona JA, Oña M, Melón S, et al. Leucoencefalopatía multifocal progresiva asociada a la infección por el virus de la inmunodeficiencia humana: características clínicas, de neuroimagen, virológicas y evolutivas de 35 pacientes. Med Clin (Barc) 1999; 113: 210-14. 